\begin{tabular}{|c|c|}
\hline Title & $\begin{array}{l}\text { Molecular identification and characterization of piroplasm species in Hokkaido sika deer (Cervus nippon yesoensis), } \\
\text { Japan }\end{array}$ \\
\hline Author(s) & $\begin{array}{l}\text { Elbaz, Elzahara; Moustafa, Mohamed A bdallah Mohamed; Lee, Kyunglee; Mohamed, Wessam Mohamed A hmed; } \\
\text { Nakao, Ryo; Shimozuru, Michito; Sashika, Mariko; Y ounis, Emad Elsay ed A hmed; El-Khodery, Sabry A hmed; } \\
\text { T subota, T oshio }\end{array}$ \\
\hline Citation & $\begin{array}{l}\text { Ticks and Tick-Borne Diseases, 8(5), 802-807 } \\
\text { https://doi.org/10.1016/.ttbdis.2017.06.007 }\end{array}$ \\
\hline Issue Date & $2017-08$ \\
\hline Doc URL & http:/hdl.handle.net/2115/71113 \\
\hline Rights & $\begin{array}{l}\text { () 2017. This manuscript version is made available under the CC-BY-NC-ND } 4.0 \text { license } \\
\text { http://creativecommons.org/icenses/by-nc-nd/4.0/ }\end{array}$ \\
\hline Rights(URL) & http://creativecommons.org/icenses/by-nc-nd/4.0/ \\
\hline Type & article (author version) \\
\hline File Information & Manuscript.pdf \\
\hline
\end{tabular}

Instructions for use 
Title: Molecular identification and characterization of piroplasm species in Hokkaido

Elzahara Elbaz $^{\mathrm{a} 1 *}$, Mohamed Abdallah Mohamed Moustafa ${ }^{\mathrm{a} 2 *}$, Kyunglee Lee ${ }^{\mathrm{b}}$,

Wessam Mohamed Ahmed Mohamed ${ }^{\mathrm{c}}$, Ryo Nakao ${ }^{\mathrm{d}}$, Michito Shimozuru ${ }^{\mathrm{a}}$, Mariko

Sashika $^{\mathrm{a}}$, Emad Elsayed Ahmed Younis ${ }^{\mathrm{e}}$, Sabry Ahmed El-khodery ${ }^{\mathrm{e}}$, Kyoko

${ }^{\mathrm{a}}$ Laboratory of Wildlife Biology and Medicine, Department of Environmental

Veterinary Sciences, Graduate School of Veterinary Medicine, Hokkaido University,

${ }^{\mathrm{b}}$ Cetacean Research Institute, National Institute of Fisheries Science, Ulsan, Republic

of Korea.

${ }^{\mathrm{c}}$ Division of bioinformatics, Hokkaido University Research Center for Zoonosis

Control, Sapporo, Hokkaido, Japan.

${ }^{\mathrm{d}}$ Laboratory of Parasitology, Department of Disease Control, Graduate School of

Veterinary Medicine, Hokkaido University, Sapporo, Japan.

${ }^{\mathrm{e}}$ Department of Internal Medicine and Infectious Diseases, Faculty of Veterinary

Medicine, Mansoura University, Mansoura, Egypt.

${ }^{\mathrm{f}}$ Division of Collaboration and Education, Hokkaido University Research Center for

1 Permanent address: Department of Internal Medicine and Infectious Diseases, Faculty of Veterinary Medicine, Mansoura University, Mansoura, Egypt.

2 Permanent address: Department of Animal Medicine, Faculty of Veterinary Medicine, South Valley University, Qena, Egypt.

* These first authors contributed equally to this article. 
Corresponding author:

Toshio Tsubota $\quad 21$

Laboratory of wildlife biology and medicine, department of environmental veterinary 22

sciences, graduate school of veterinary medicine, Hokkaido University, Sapporo, 23

$\begin{array}{ll}\text { Japan. } & 24\end{array}$

Address: 060-0818, North 18 West 9 Sapporo, Hokkaido, Japan. 25

Email: tsubota@vetmed.hokudai.ac.jp 26 
Babesia and Theileria species are tick-borne protozoan parasites that have a

veterinary and zoonotic importance. In order to investigate the prevalence and genetic

diversity of these parasites, a total of 269 sika deer blood DNA samples collected

from Hokkaido, Japan, were examined for Babesia and Theileria species by touch-

49

down PCR targeting the 18S rRNA gene. Reverse line blot (RLB) hybridization was

50

then used to detect 12 piroplasm species. The results revealed that $95.5 \%$ (257/269),

$94.1 \%$ (253/269), $14.1 \%$ (38/269), $87.7 \%$ (236/269) and $11.5 \%(31 / 269)$ of the

examined PCR products hybridized with the probes which were designed to detect all

Babesia and Theileria spp., all Theileria spp., all Babesia spp., Theileria sp. Thrivae

and Babesia divergens-like, respectively. The 18S rRNA gene partial sequences were 
Babesia and Theileria species are tick-borne protozoan parasites that have a

veterinary and zoonotic importance (Mans et al., 2015). Babesia and Theileria spp.

69

are obligatory intracellular parasites and genetically close to each other (Homer et al., $\quad 70$

2000), however, both have different life cycles. In the mammalian host, Babesia spp. 71

sensu stricto infect erythrocytes (Schreeg et al., 2016), while Theileria spp. infect both 72

leukocytes and erythrocytes ( $\mathrm{Li}$ et al., 2014). 73

In cattle, East Coast fever and tropical theileriosis are caused by T. parva and $T$.

annulata, respectively, and exhibit fever, enlargement of lymph nodes and weight loss

(Mans et al., 2015; Olds et al., 2016). In addition, B. bovis and B. bigemina are highly 76

pathogenic in cattle and cause bovine babesiosis, a diseases which shows fever,

hemolytic anemia and hemoglobinuria (Decaro et al., 2013). Babesia ovis, B. motasi 78

and B. crassa cause sever disease in sheep which is characterized by anemia, fever, $\quad 79$

icterus and hemoglobinuria (Hashemi-Fesharki, 1997). 80

To the best of our knowledge, there is no published description of clinical

manifestations in sika deer (Cervus nippon yesoensis) with piroplasmosis. However,

clinical piroplasmosis may occur in the case of exposure to high stressful conditions

such as malnutrition (Yabsley et al., 2005). The clinical symptoms of theileriosis in a

white-tailed deer (Odocoileus virginianus) fawn were previously reported from the

USA and included icterus and anemia (Yabsley et al., 2005).

One of the zoonotic Babesia spp. is B. divergens, which has been reported from

several deer species including reindeer, roe deer and red deer in Europe (Michel et al., 
detected in cervids, for example T. cervi, which is a non-pathogenic Theileria sp. that

has been reported from white-tailed deer and elk (Cervus canadensis) in USA and

Canada (Chae et al., 1999). However, another T. cervi, which is genetically separated

from T. cervi in the USA and Canada, has been found in sika deer from China (Liu et

al., 2016), but has been reported as Theileria sp. Thrivae in Japan (Watanabe et al.,

95

2016). Nevertheless, all Theileria spp. have not been recognized as zoonotic

96

pathogens (Zanet et al., 2014).

The sika deer (Cervus nippon) is widely distributed in Asia and acts as a reproductive

host for several tick species such as Heamaphysalis longicornis, H. flava, H. Yeni, H.

megaspinosa, H. Formosensis, H. kitaokai and Ixodes ovatus were detected on sika

deer in Japan (Inokuma et al., 2002). In Japan, sika deer populations have an

important role in maintaining several tick-borne pathogens, such as Anaplasma sp.

Ap-sd (Moustafa et al., 2015), Theileria sp. Thrivae (Watanabe et al., 2016), B.

divergens-like (Zamoto-Niikura et al., 2014) and Borrelia lonestari-like (Lee et al.,

2014) . In Hokkaido, sika deer population density has been expanding (Ijima et al.,

2015) and they live in close proximity to human settlements and livestock.

Consequently, sika deer may facilitate the transmission of several tick-borne

pathogens to both humans and livestock.

In spite of the enormous research on the role of sika deer in the transmission of tickborne pathogens, a continuous survey is needed to detect the new emerging

piroplasmids in sika deer in Japan. Previously, conventional polymerase chain

reactions (PCR) have been used to detect Babesia and Theileria spp. in Japan

(Watanabe et al., 2016). Here, the reverse line blot hybridization (RLB) was applied in this study for the specific detection of 12 different piroplasm species. This 
of samples (Kong and Gilbert, 2006) with high specificity and less cost than

sequencing a large number of samples. The objective of this study was to estimate the

infection rates and molecular characterization of several Babesia and Theileria spp.

among sika deer in Hokkaido.

Materials and methods

Blood samples and DNA extraction

Whole blood samples were obtained from the jugular vein of 269 sika deer (C. nippon

yesoensis) that were culled for nuisance control during 2010 to 2013 from Hokkaido

123

prefecture, Japan. These blood samples were collected in EDTA-Na containing tubes

and stored at $-20^{\circ} \mathrm{C}$ until used. DNA was extracted from the blood samples by using

the Wizard ${ }^{\circledR}$ Genomic DNA purification Kit (Promega, Madison, WI, USA) as per

manufacturer's instructions and kept at $-20^{\circ} \mathrm{C}$ until analysis.

Touch-down Polymerase Chain Reaction (PCR)

A touch-down PCR targeting the 18S rRNA gene of Babesia and Theileria species

was performed by using PCR System 9700 (Applied Biosystems, Foster City, CA),

QIAGEN Multiplex PCR kits (Qiagen, Hilden, Germany) and the primer pair RLB-F2

and RLB-R2 (Gubbels et al., 1999; Matjila et al., 2004). To amplify a 460-540 bp

fragment, PCR mixtures composed of $9 \mu \mathrm{l}$ of molecular grade water, $1.25 \mu \mathrm{l}$ of each

primer (10 pmol), $12.5 \mu \mathrm{l}$ of 2 x QIAGEN Multiplex PCR Master Mix and $1 \mu$ DNA.

The PCR consisted of an activation step at $94^{\circ} \mathrm{C}$ for 15 min, a touch down step of 12

cycles at $94{ }^{\circ} \mathrm{C}$ for $30 \mathrm{~s}, 69^{\circ} \mathrm{C}$ for $90 \mathrm{~s}$ and $72{ }^{\circ} \mathrm{C}$ for $90 \mathrm{~s}$ with annealing temperature

decreasing every cycle by $1^{\circ} \mathrm{C}$. This followed by 40 cycles at $94^{\circ} \mathrm{C}$ for $30 \mathrm{~s}, 57^{\circ} \mathrm{C}$ for

$90 \mathrm{~s}$ and at $72^{\circ} \mathrm{C}$ for $90 \mathrm{~s}$ and a final extension step at $72^{\circ} \mathrm{C}$ for $10 \mathrm{~min}$. PCR products 
examined by electrophoresis through $1 \%$ agarose gel and visualized by UV

illuminator.

Oligonucleotide probes and reverse line blot $(R L B)$ hybridization

A total of 8 newly designed and 9 previously published oligonucleotide probes (Table

1) were received from Sigma Aldrich Co., LLC, Japan. The probe designing process

was performed according to (Kong and Gilbert, 2006). Briefly, the 18S rRNA gene

sequences for the target pathogens (Table 1) were downloaded from the GenBank and

aligned by using MEGA software version 6 (Tamura et al., 2013). The probe

sequences were selected for each target and evaluated by OligoEvaluator software

(Sigma Aldrich, MO, USA) to ensure optimum physical characteristics. Finally, the

selected probe sequences were searched in the Nucleotide Basic Local Alignment

Search Tool (BLASTn) (Altschul et al., 1990) and tested against the positive control samples to ensure its specificity.

RLB was carried out with the PCR products as described before (Kong and Gilbert,

(EDAC) (Sigma Aldrich, MO, USA). The membrane was washed gently with milliQ

water for 2 min and placed in Miniblotter MN45 (Immunetics, Boston, Massa-

chusetts). A total of 17 oligonucleotide probes (Table 1) linked with C6 amino linker

solutions. Ten microliters of each $100 \mathrm{pmol} / \mu \mathrm{l}$ probes were diluted in $0.5 \mathrm{M}$ NaHCO3

to a final volume of $170 \mu$ l. The openings of the miniblotter were filled with a $150 \mu \mathrm{l}$ 
for exactly $8 \mathrm{~min}$ at room temperature, then washed at $60^{\circ} \mathrm{C}$ with prewarmed $250 \mathrm{ml}$

of $2 \times$ SSPE/0.1\% SDS. Finally, the membrane was kept with $15 \mu \mathrm{l}$ of $20 \mathrm{mM}$ EDTA

in a sealed plastic bag for the future use.

A total of $10 \mu$ of each PCR product was diluted in $2 \times$ SSPE/0.1\% SDS to a final

volume of $170 \mu \mathrm{l}$ and denatured by heating at $99.9^{\circ} \mathrm{C}$ for $10 \mathrm{~min}$ and immediately

cooled on ice. The denatured mixtures were introduced to the membrane, and

hybridized at $60^{\circ} \mathrm{C}$ for $1 \mathrm{hr}$. Afterwards, this membrane was washed in $250 \mathrm{ml}$ of $2 \times$

SSPE $/ 0.5 \%$ SDS twice at $52^{\circ} \mathrm{C}$ for $10 \mathrm{~min}$ and then incubated with diluted peroxidase

labeled NeutrAvidine (Thermo Fisher Scientific, Walyham, MA, USA) for 45-60 min

at $42^{\circ} \mathrm{C}$. Subsequently, NeutrAvidine was washed away by $250 \mathrm{ml} 2 \times \mathrm{SSPE} / 0.5 \%$

SDS twice at $42^{\circ} \mathrm{C}$ for $10 \mathrm{~min}$ and $2 \times \mathrm{SSPE}$ twice at room temperature for $5 \mathrm{~min}$. To

visualize the results, the membrane was exposed for 5 min to $15 \mathrm{ml} \mathrm{Immobilon}{ }^{\mathrm{TM}}$

Western Chemiluminescent HRP Substrate (Millipore, Japan), and photographed by

Ez-Capture MG/ST (ATTO Corp., Japan). To remove the PCR products, the

membrane was washed twice in pre-warmed $1 \%$ SDS at $90^{\circ} \mathrm{C}$ for $30 \mathrm{~min}$ and washed

with $250 \mathrm{ml}$ of $20 \mathrm{mM}$ EDTA. For the future reuse, the membrane was kept with 15

\section{Cloning and sequencing}

To confirm RLB results, randomly selected twenty-one RLB-positive PCR products

Theileria sp. Thrivae, Babesia divergens-like and all Babesia and Theileria spp.,

respectively. To amplify a fragment of 460-540 bp from 18S rRNA gene of piroplasm 
Neo buffer, $2.5 \mu \mathrm{l}$ of dDNTPs (2mM), $1.5 \mu \mathrm{l}$ of $25 \mathrm{mM}$ MgSO4, $0.75 \mu \mathrm{l}$ of each

primer (10 pmol), $0.5 \mu$ l of KOD-Plus-Neo DNA polymerase and $1 \mu \mathrm{l}$ of DNA. The

PCR conditions were $2 \mathrm{~min}$ at $94^{\circ} \mathrm{C}$ and 40 cycles of $10 \mathrm{~s}$ at $98^{\circ} \mathrm{C}, 30 \mathrm{~s}$ at $57^{\circ} \mathrm{C}$ and 30

$\mathrm{s}$ at $68^{\circ} \mathrm{C}$, followed by a final extension $7 \mathrm{~min}$ at $68^{\circ} \mathrm{C}$. The PCR products were

examined by electrophoresis and the positive bands at 460-540 bp were excised for

purification by NucleoSpin ${ }^{\circledR}$ Gel and PCR clean up (Macherey-Nagel, GM \& CO KG,

195

Germany). The purified PCR products were sequenced by using the Big- Dye

Terminator version 3.1 Cycle Sequencing Kit and purified by BigDye ${ }^{\circledR}$

XTerminator $^{\mathrm{TM}}$ Purification Kit (Life Technologies Co., NY, USA). Subsequently,

the purified products were sequenced by ABI PRISMTM 310 genetic analyzer (Life

Technologies Co., NY, USA). BLASTn (Altschul et al., 1990) searches were

performed to compare the obtained sequences to reference sequences recorded in

GenBank for identification.

202

A total of 3 sequencing results with mixed signals were resolved by TA cloning. The 203

purified PCR products were A-attached by mixing $0.9 \mu$ l of $10 \times$ KOD-Plus-Neo

buffer, $0.9 \mu \mathrm{l}$ of $2 \mathrm{mM}$ dDNTPs, $0.54 \mu \mathrm{l}$ of $25 \mathrm{mM}$ MgSO4, $6.66 \mu \mathrm{l}$ of each purified

PCR product and $1 \mu \mathrm{l}$ of $10 \times \mathrm{A}$-attachment mix (Toyobo Co. Ltd.) at $60^{\circ} \mathrm{C}$ for $10 \mathrm{~min}$.

206

One microliter of each A-attached product was cloned with pMD20 T-vector (Takara

207

Bio, Otsu, Japan). Five colonies per sample were selected and screened by

208

EmeraldAmp MAX PCR (Takara Bio, Otsu, Japan) as described in the manufacturer's

manual and sequenced as mentioned above. When a sequence was detected from one

clone, more 5 clones from the same sample were sequenced. The sequences were 
A total of twenty-two 18S rRNA partial sequences were submitted to DDBJ. The

accession numbers were: (LC271196 - LC271213) from the direct sequencing of

215

eighteen PCR products and (LC215385 - LC215388) from cloning and sequencing of

216

three other PCR products. The obtained sequences were identified by using BLASTn

search against the sequences of Babesia and Theileria spp. in the GenBank. The

divergence distances between sequences were calculated by the Maximum Composite

Likelihood model in MEGA software version 6 (Tamura et al., 2013). The

220

evolutionary distance matrix was visualized as a heat map (Fig. 3 \& 4) that was

221

developed by using the R Stats package in the R studio software (http://www.R-

project.org/).

\section{Results}

A total of 269 sika deer blood DNA samples were molecularly screened for the

presence of Babesia and Theileria species by touch-down PCR and RLB

hybridization using 17 oligonucleotide probes (Table 1). The specificity of the newly

designed 8 oligonucleotide probes was ensured through examining the genomic DNA

samples of B. microti-US type, B. microti-Hobetsu type, $B$. rodhaini, $B$. divergens-

like, $B$. bovis, $B$. bigemina, Theileria sp. Thrivae and T. orientalis positive controls

(Fig. 1).

The results showed that 95.5\% (257/269), 94.1\% (253/269), 14.1\% (38/269), 87.7\%

Theileria sp. Thrivae and B. divergens-like oligonucleotide probes (Table 2),

respectively. In addition, 10.0\% (27/269) of the PCR products hybridized with both

Theileria sp. Thrivae and B. divergens-like oligonucleotide probes, while 6.3\% 
all probes, but negative for all species-specific probes (Fig. 2). Interestingly, 2.6\%

(7/269) hybridized with Babesia / Theileria spp. catch-all, Theileria spp. catch-all,

Theileria sp. Thrivae and Babesia spp. 1 catch-all probes, but were negative for all

Babesia spp. species-specific probes (Fig. 2).

The obtained 18S rRNA partial gene sequences were mainly divided into two

Theileria and two Babesia spp. (Fig. 3 \& 4). The similarity between the accession

numbers (LC271208 - LC271213 and LC215385) was from 99 to 100\%. Whereas

sequence accession numbers (LC271196 - LC271207 and LC215386) were 99 - 100\%

similar to each other. The obtained sequence (LC215385) was identical to T. cervi

(KT863532) from sika deer in China and 99\% similar to Theileria sp. (AB012199 \&

AB012194) from sika deer in Japan, whereas sequence (LC215386) was identical to

Theileria sp. (AB012189) from sika deer in Hokkaido, Japan and 99\% similar to T.

250

capreoli (KJ188219) from red deer in China. In addition, the obtained sequence

(LC215387) was identical to B. divergens-like (KC465973 \& KC465975) from sika Hj42 (GU057380) from Haemaphysalis japonica in Russia.

\section{Discussion}

Sika deer act as reproductive hosts for several tick species, which may transmit

several tick-borne pathogens to wildlife, livestock and human beings (Watanabe et al.,

257

2016). During the last two decades, numbers of sika deer (C. nippon) populations in

Hokkaido have been increasing (Ijima et al., 2015). In Japan, previous studies stated

(Ikawa et al., 2011; Inokuma et al., 2004; Zamoto-Niikura et al., 2014). In this study, 
piroplasm species; B. divergens-like, undescribed Babesia sp., Theileria sp. Thrivae

and T. capreoli. Unfortunately, no species-specific oligonucleotide probes were

designed for the detected Babesia sp. and T. capreoli; both organisms were detected

in this study by cloning and sequencing. The respective infection rates of the $B$.

divergens-like (11.5\%) and Theileria sp. Thrivae (87.7\%) detected in this study were

similar to and higher than previously published reports from Japan (Ikawa et al., 2011;

269

Watanabe et al., 2016; Zamoto-Niikura et al., 2014). This is possibly due to the higher

270

sensitivity of RLB technique than conventional PCR assays. The hybridization results

271

were confirmed by sequencing, which showed that all obtained sequences have the

same hybridization sites as their species-specific probes. However, a total of 7 and 17

PCR products, which were hybridized with the respective catch-all probes for Babesia

and Theileria species, were negative for all other Babesia and Theileria species-

275

specific probes.

The obtained partial 18S rRNA gene sequences were divided into two Babesia and two Theileria species. One Babesia sp. clustered with the previously published $B$. divergens-like (Fig. 3) from sika deer in Japan (Zamoto-Niikura et al., 2014). The

second Babesia sp. sequence was completely separated from the other Babesia spp.

and clustered with a Babesia sp. which was detected in Haemaphysalis japonica from

Russia (Fig. 3). Hence, additional research on this Babesia sp. is required to fully

The phylogenetic position of the detected Theileria spp. in the sika deer of this study was among the benign theileriosis group, which includes T. orientalis and T. buffeli

(Inokuma et al., 2008; Li et al., 2014). One Theileria spp. cluster was very similar to

Theileria sp. Thrivae (Fig. 4), which was reported from sika deer in Japan (Watanabe 
cluster was completely divergent from T. cervi (U97054) that was detected in white-

tailed deer and elk (Cervus canadensis) from the USA and Canada (Fig. 4),

respectively (Chae et al., 1999). The second Theileria spp. cluster was closely related

to T. capreoli (Fig. 4). Previously, T. capreoli 18S rRNA gene sequence (AB012189)

was deposited into the GenBank from Japan, however, this study was not published.

previously reported from Japan (Watanabe et al., 2016), was not detected in this study.

295

\section{Conclusions}

This study identified the role of sika deer in maintaining 4 different tick-borne

infection rates and T. capreoli needing more examinations to understand its ecology.

Furthermore, a potentially novel Babesia sp. was detected in the sika deer samples of

this study. However, this study lacks information about the prevalence of the

undescribed Babesia sp. and T. capreoli in sika deer in Hokkaido. Future

investigations will also be needed to identify the vector hosts for these organisms to

fully understand the ecology of piroplasm spp. in Japan.

\section{Competing interests}

The authors declare that they have no competing interests.

\section{Acknowledgements}

This study was supported in part by the Program for Leading Graduate Schools

"Fostering Global Leaders in Veterinary Science for Contributing to One Health"

grant no. (F01), MEXT, Japan and the Mitsui \& Co., Ltd. Environment Fund. The

authors gratefully acknowledge Professor Xuenan Xuan and Dr. Paul Franck Adjou 
Agriculture and Veterinary Medicine, Japan) for providing us with the genomic DNA samples of the positive controls.

Reference

Altschul, S.F., Gish, W., Miller, W., Myers, E.W., Lipman, D.J., 1990. Basic local

alignment search tool. J. Mol. Biol. 215, 403-410.

Chae, J.S., Waghela, S.D., Craig, T.M., Kocan, A.A., Wagner, G.G., Holman, P.J.,

1999. Two Theileria cervi SSU RRNA gene sequence types found in isolates from

Decaro, N., Larocca, V., Parisi, A., Losurdo, M., Lia, R.P., Greco, M.F., Miccolis, A.,

Gubbels, J.M., de Vos, A.P., van der Weide, M., Viseras, J., Schouls, L.M., de Vries,

Hashemi-Fesharki, R., 1997. Tick-borne diseases of sheep and goats and their related vectors in Iran. Parassitologia 39, 115-117.

Homer, M.J., Aguilar-Delfin, I., Telford, S.R., Krause, P.J., Persing, D.H., 2000.

Ijima, H., Fujimaki, A., Ohta, U., Yamamura, K., Yokomizo, H., Uno, H., Matsuda, 
Inokuma, H., Fujimoto, T., Hosoi, E., Tanaka, S., Fujisaki, K., Okuda, M., Onishi, T.,

Inokuma, H., Tsuji, M., Kim, S.J., Fujimoto, T., Nagata, M., Hosoi, E., Arai, S ,.

Ishihara, C., Okuda, M., 2004. Phylogenetic analysis of Theileria sp. from sika deer,

Kong, F., Gilbert, G.L., 2006. Multiplex PCR-based reverse line blot hybridization

Lee, K., Takano, A., Taylor, K., Sashika, M., Shimozuru, M., Konnai, S., Kawabata, 350

H., Tsubota, T., 2014. A relapsing fever group Borrelia sp. similar to Borrelia

Li, Y., Chen, Z., Liu, Z., Liu, J., Yang, J., Li, Q., Li, Y., Cen, S., Guan, G., Ren, Q., 
Mans, B.J., Pienaar, R., Latif, A.A., 2015. A review of Theileria diagnostics and

Matjila, P.T., Penzhorn, B.L., Bekker, C.P., Nijhof, A.M., Jongejan, F., 2004.

Confirmation of occurrence of Babesia canis vogeli in domestic dogs in South Africa.

Michel, A.O., Mathis, A., Ryser-Degiorgis, M.P., 2014. Babesia spp. in European

Moustafa, M.A., Lee, K., Taylor, K., Nakao, R., Sashika, M., Shimozuru, M., Tsubota,

Moustafa, M.A., Taylor, K., Nakao, R., Shimozuru, M., Sashika, M., Rosa, R., Thu, 
Schreeg, M.E., Marr, H.S., Tarigo, J.L., Cohn, L.A., Bird, D.M., Scholl, E.H., Levy, 379

M.G., Wiegmann, B.M., Birkenheuer, A.J., 2016. Mitochondrial genome sequences 380

and structures aid in the resolution of Piroplasmida phylogeny. PLoS One 11, 381

e0165702. 382

Tamura, K., Stecher, G., Peterson, D., Filipski, A., Kumar, S., 2013. MEGA6: 383

Molecular evolutionary genetics analysis version 6.0. Mol. Biol. Evol. 30, 2725-2729. 384

Watanabe, Y., Fukumoto, S., Harasawa, R., 2016 .Prevalence of tick-borne hemolytic 385

microbes in Free-living sika deer (Cervus nippon) captured in a deer-overcrowded 386

area. Japanese Journal of Zoo and Wildlife Medicine 21, 17-27. 387

Yabsley, M.J., Quick, T.C., Little, S.E., 2005. Theileriosis in a white-tailed deer 388

(Odocoileus virginianus) fawn. J. Wildl. Dis. 41, 806-809. 389

Zamoto-Niikura, A., Tsuji, M., Imaoka, K., Kimura, M., Morikawa, S., Holman, P.J., 390

Hirata, H., Ishihara, C., 2014. Sika deer carrying Babesia parasites closely related to B. 391

divergens, Japan. Emerg Infect Dis 20, 1398-1400. 392

Zanet, S., Trisciuoglio, A., Bottero, E., de Mera, I.G., Gortazar, C., Carpignano, M.G., 393

Ferroglio, E., 2014. Piroplasmosis in wildlife: Babesia and Theileria affecting free- 394

ranging ungulates and carnivores in the Italian Alps. Parasites \& Vectors 7, 70.

396

397

398

399

400 


\begin{tabular}{|c|c|c|}
\hline Probe & Sequence (5'-3') & Reference \\
\hline Babesia /Theileria all & TAATGGTTAATAGGARCRGTWG & Moustafa et al. (2016) \\
\hline Theileria spp. all & ATTAGAGTGCTCAAAGCAGGC & Matjila et al. (2008) \\
\hline Babesia spp. all 1 & ATTAGAGTGTTTCAAGCAGAC & Matjila et al. (2008) \\
\hline Babesia spp. all 2 & ACTAGAGTGTTTCAAACAGGC & Matjila et al. (2008) \\
\hline B. microti all & GRCTTGGCATCWTCTGGA & Matjila et al. (2008 \\
\hline B. microti Otsu and Hobetsu & GGGTACTGTTTCCAGGGT & This study \\
\hline B. microti US & GGGTACTATTTTCCAGGAT & This study \\
\hline B. gibsoni & TACTTGCCTTGTCTGGTTT & Matjila et al. (2008) \\
\hline B. divergens-like & TTAATCATAACWGATGTTTTG & This study \\
\hline B. rodhaini & TGTGGATTAGTGCGCAAG & This study \\
\hline B. bigemina & CTCGTAGTTGTATTTCAGCCT & This study \\
\hline B. bovis & GAGCATGGAATAACCTTGTAT & This study \\
\hline B. venatorum & GAGTTATTGACTCTTGTCTTTAA & Gigandet et al. (2011) \\
\hline B. divergens \& B. capreoli & GGTGTTAATATTGACTRATGTCGAG & Moustafa et al. (2016) \\
\hline B. duncani & AGTTGAACTTCTGCCGCTT & Moustafa et al. (2016) \\
\hline Theileria sp. Thrivae & ACGAGTGTCTGTATTGCG & This study \\
\hline Theileria orientalis /buffeli / sergenti & TTTGAGTTTGTTATTGTGG & This study \\
\hline
\end{tabular}

TABLE 1 List of Babesia and Theileria spp. and their oligonucleotide probes used

for its detection 


\begin{tabular}{lllllll}
\hline & & Babesia /Theileria all & Theileria spp. all & Babesia spp. all 1 & Theileria sp. Thrivae & B. divergens-like \\
\hline Fawn & 108 & $102(94.4)$ & $98(90.7)$ & $26(24.1)$ & $86(79.6)$ & $25(23.1)$ \\
Adult & 161 & $155(96.3)$ & $155(96.3)$ & $12(7.5)$ & $150(93.2)$ & $6(3.7)$ \\
Total & 269 & $257(95.5)$ & $253(94.1)$ & $38(14.1)$ & $236(87.7)$ & $31(11.5)$ \\
\hline
\end{tabular}

TABLE 2 Summary of Babesia and Theileria spp. detection in sika deer blood 
FIG 1 Validation of the newly designed oligonucleotide probes in this study. RLB

Babesia and Theileria catch all

Theileria spp. all Babesia spp. I Babesia spp. 2 Theileria orientalis / buffeli/ sergenti Theileria sp. thrivae B. gibsoni $B$. bigemina B. bovis $B$. divergens \& B. capreoli $B$. venatorion

$B$. divergens like B. dionconi B. rodhaini B. microti US B. microti Otsu and Hobetsu B. microti all Babesia spp. 2 Babesia spp. 1 Theileria spp. all $B$ abesia and Theileria catch all

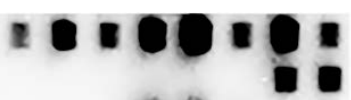

$0 \mathrm{x}$

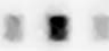

441

442

443

444

445

446

447

448

449

450

451

452

453

454

455

456 


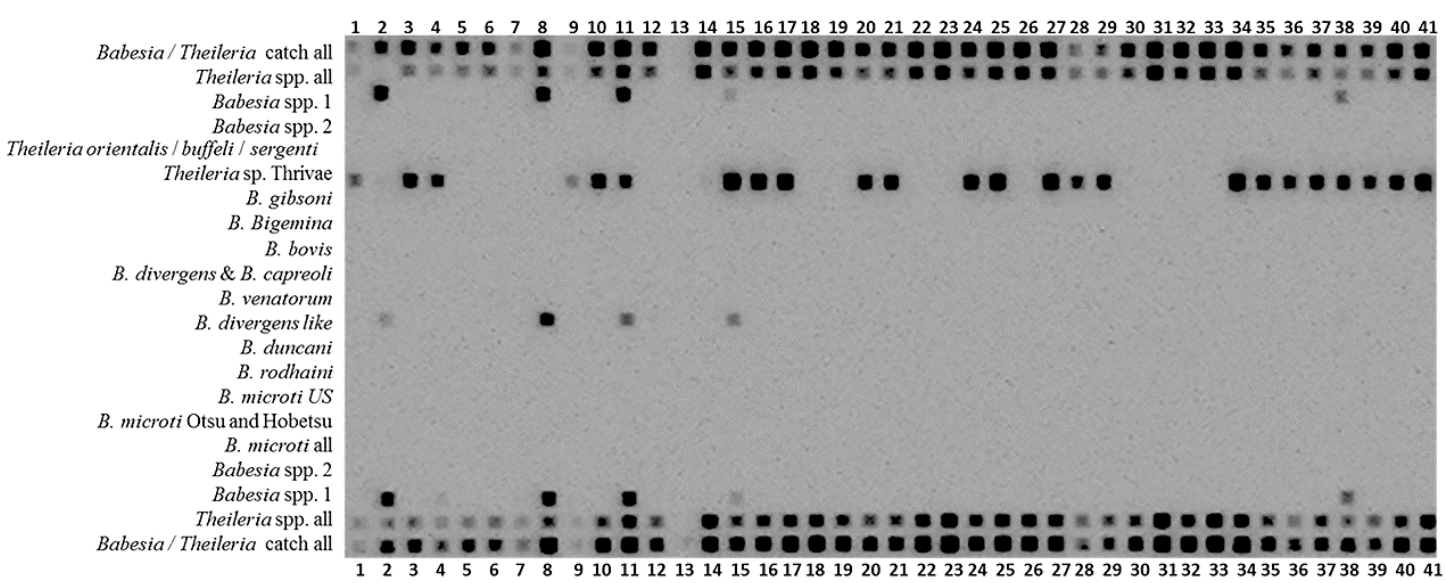


FIG 3 Phylogenetic relationship between 18S rRNA gene sequences of Babesia spp.

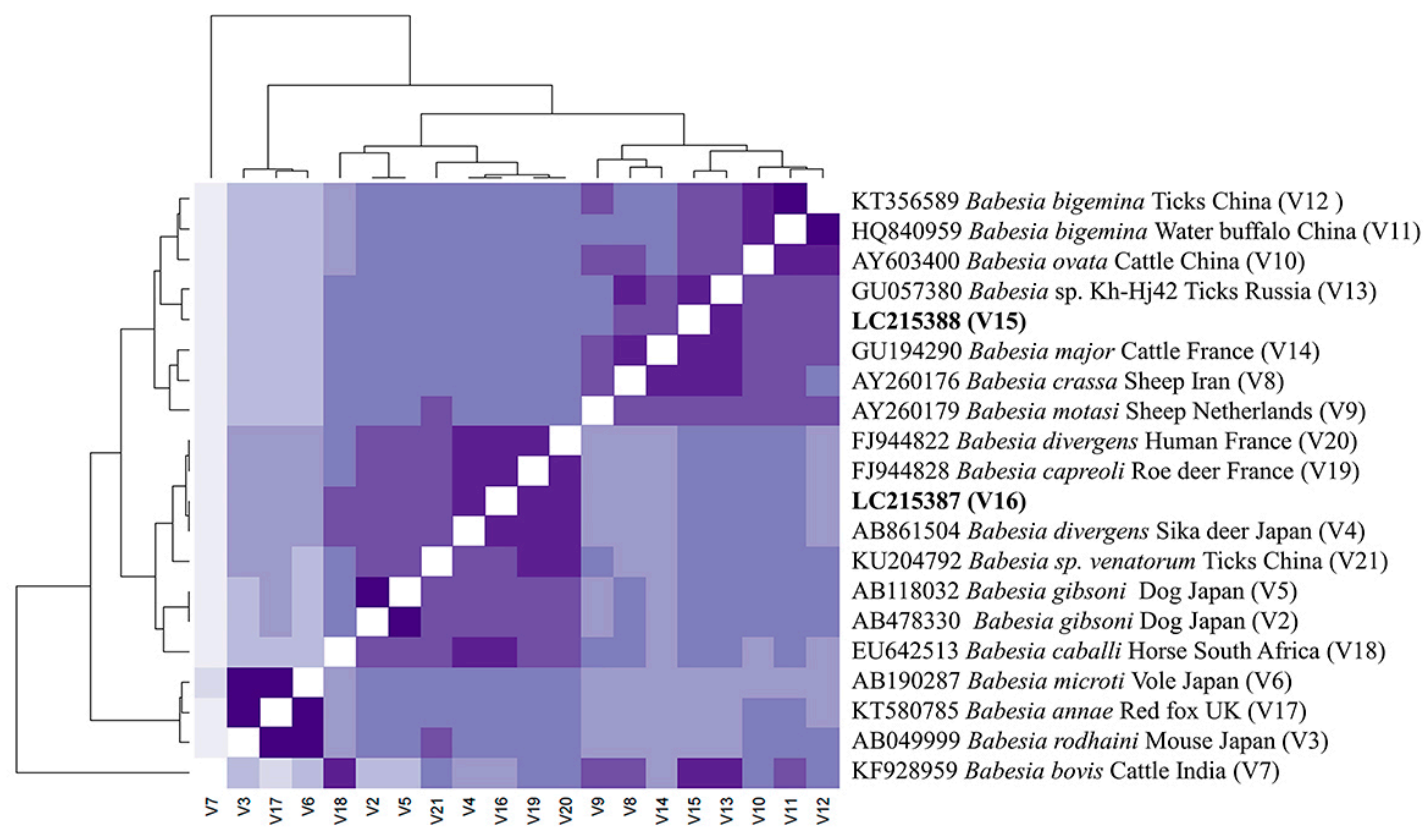


FIG 4 Phylogenetic relationship between 18S rRNA gene sequences of Theileria spp.

from GenBank. Sequences from the current study are labeled in bold. The DNA

and LC215386. The evolutionary distance matrix is visualized as a heat map. In the

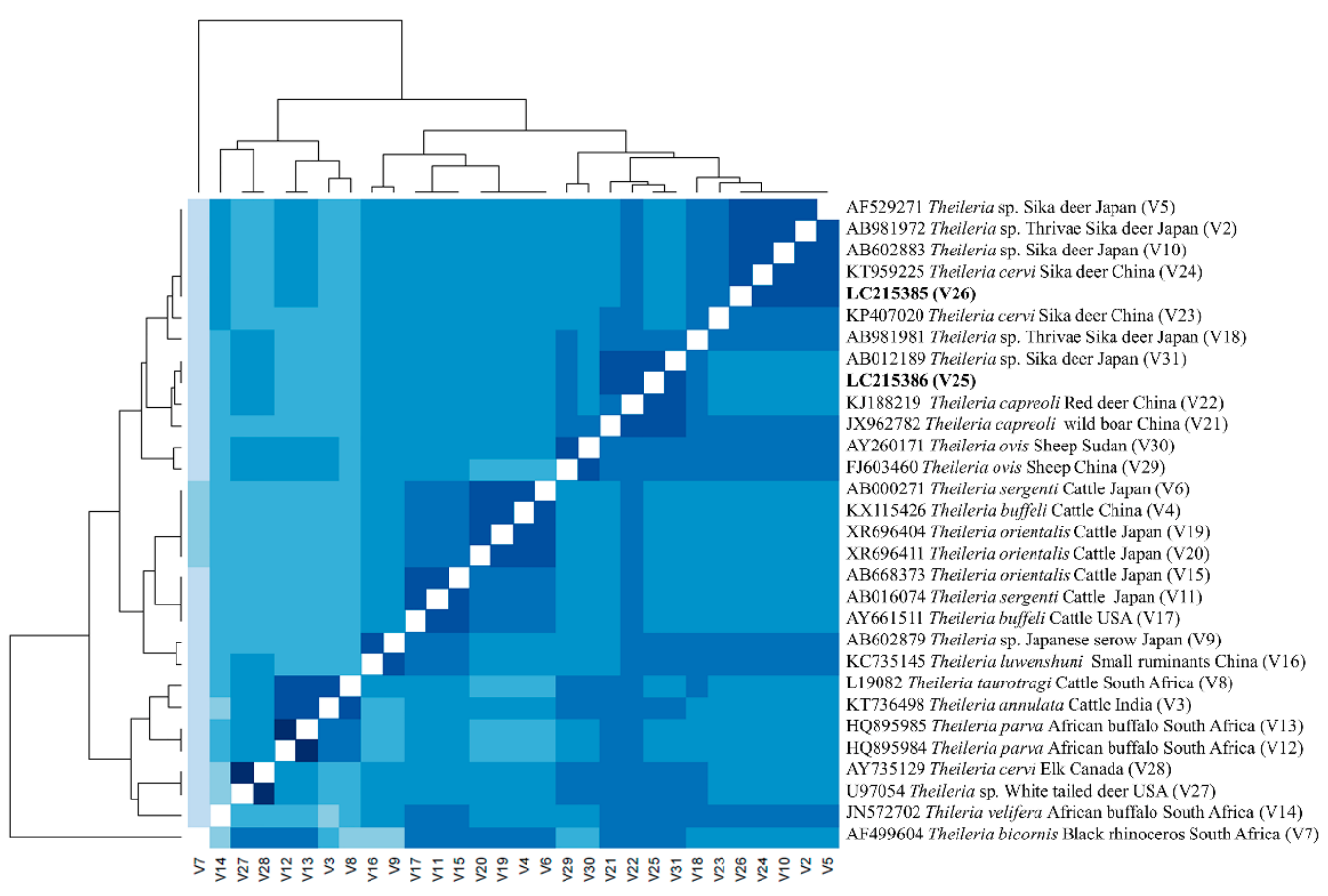

